Graduate Students, Science and Engineering

\title{
Development of Sustainable Eco-friendly Geopolymer Composites for Construction Applications
}

\author{
Mohamed Rabie, Mohammad R. Irshidat, Nasser Al-Nuaimi
}

Center for Advanced Materials, Qatar University Doha 2713, Qatar

\section{Abstract}

Geopolymerization is a process where silica and alumina rich source materials turns into excellent binding materials by the aid of alkali solutions. Materials such as fly ash are by-products in energy power plants. Fly ash is classified based on its constituent materials. Fly ash class $\mathrm{F}$ mainly consists of alumina and silica. Compressive strength of class $\mathrm{F}$ fly ash geopolymer mortar is influenced by many factors such as the molarity of sodium hydroxide solution, fluid to binder ratio $\mathrm{Na} 2 \mathrm{SiO} / \mathrm{NaOH}$ ratio, curing duration and curing temperatures. The present study investigates the effect of these factors on the compressive strength of geopolymer mortar. For each combination, three cubes with dimensions of $50 \times 50 \times 50 \mathrm{~mm}$ were casted. After heat curing in the laboratory oven, the samples were tested on a universal testing machine for the compressive strength.

The results showed very high early compressive strength of $63.9 \mathrm{MPa}$ for samples cured at $80^{\circ} \mathrm{C}$ and for a duration of $24 \mathrm{hr}$.

\section{Aims and Objectives}

The aim of this study is to investigate the factors influencing the mechanical properties of geopolymer mortar (GPM), and what are the best practices and optimum conditions.

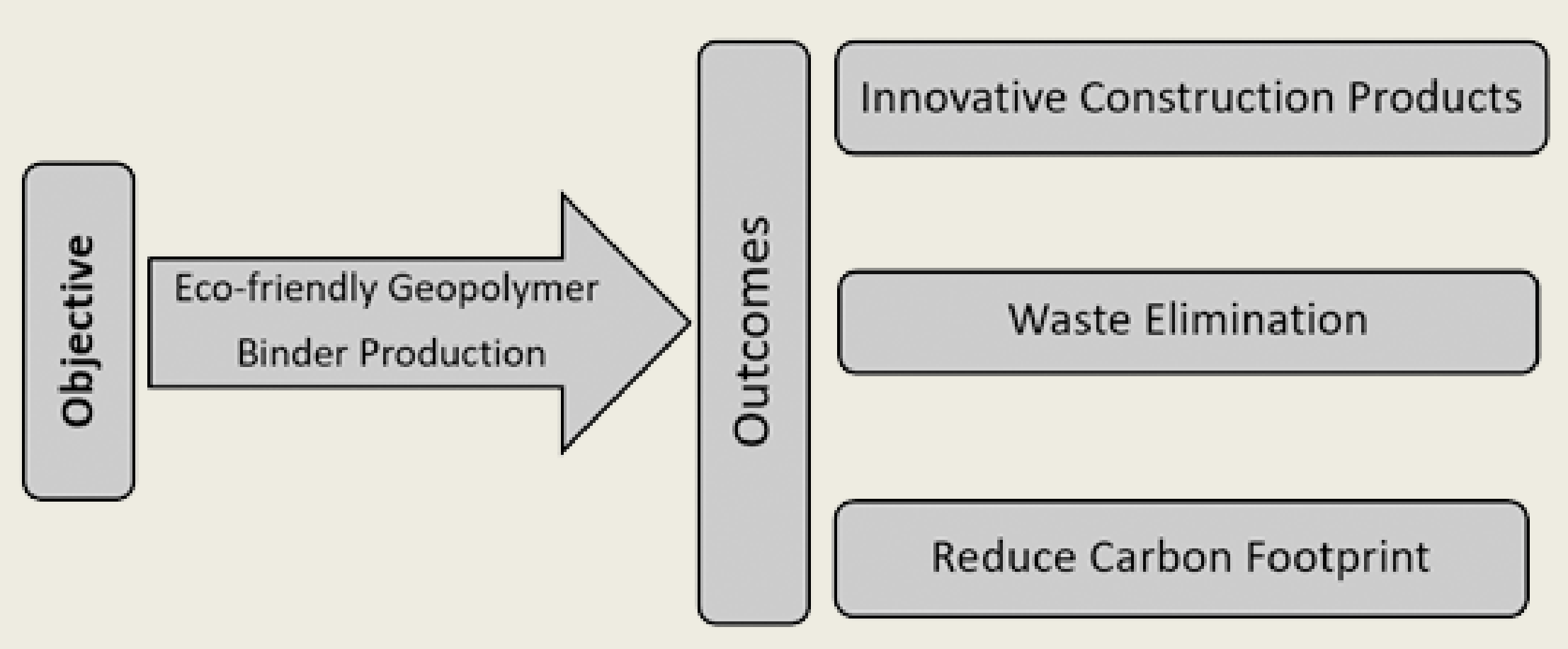

Significance

This research of high significance as it will:

- Allow for establishing methods for production of high strength geopolymer mortar that can be used in civil engineering applications.

- Reducing the environmental impact of the construction industry due to the use of traditional construction material and using source materials to produce binding materials with outstanding mechanical properties.

\section{Research Motivation}

Cement production processes requires immense amount of energy and is accountable for $7 \%$ carbon dioxide emissions to the atmosphere. It is estimated that production of one ton of cement is equivalent to one ton of $\mathrm{CO} 2$ (Alnahhal et al. 2017; Ng et al. 2018; Singh et al. 2015). There has been an increasing demand to develop a new binding material that can partially or fully replace cement in mortar and concrete. Geopolymerization is a process where three-dimensional polymeric chain rings consisting of Si-O-Al-O are formed by alkali activating the source material that are rich with silica and alumina (Rattanasak and Chindaprasirt 2009). The geopolymerization process is summarized in Figure 3 .
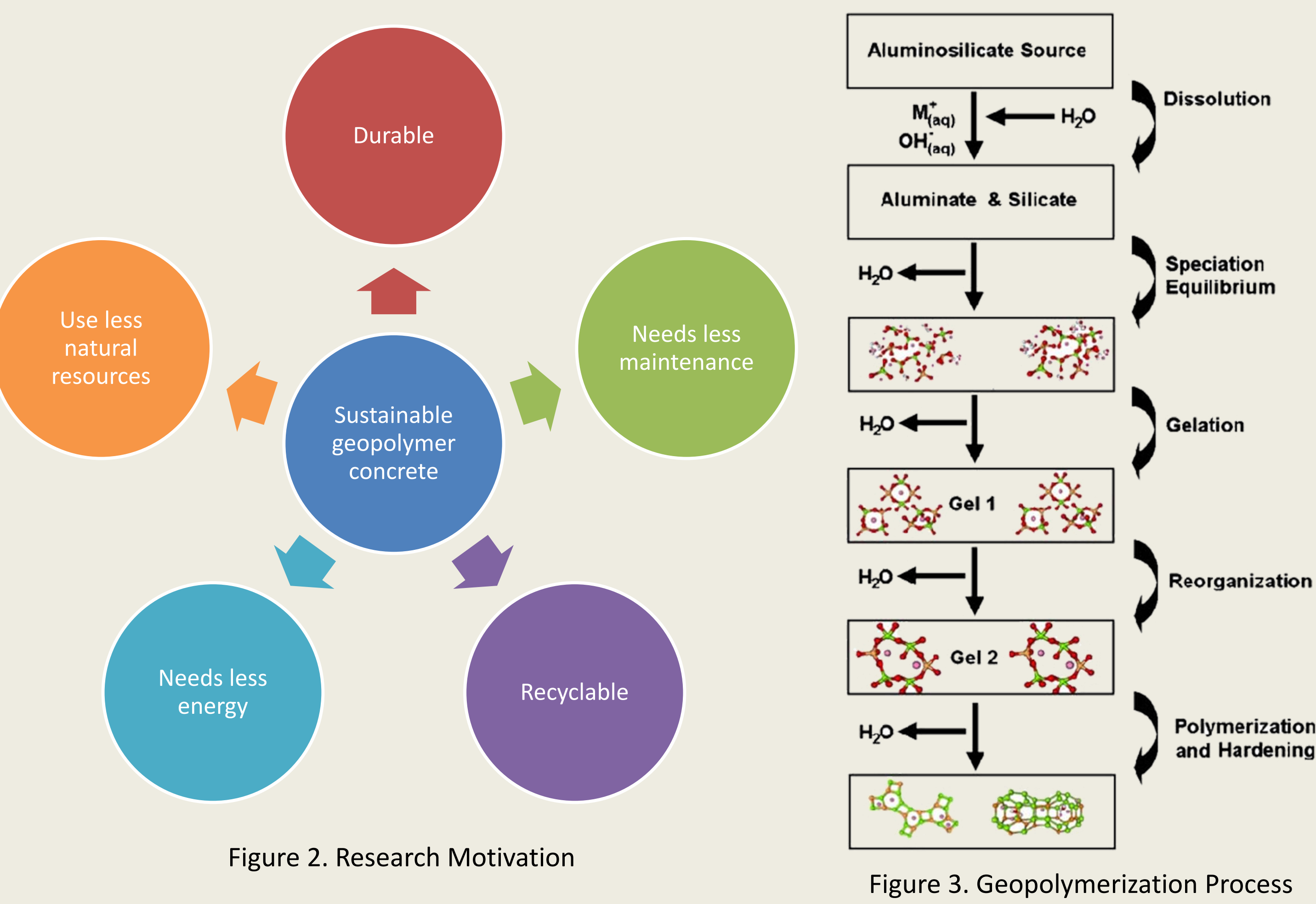

Methods and Materials

Materials:

- Sand

- Fly Ash class F

- Activator Solution

Sodium hydroxide 12,14 and $16 \mathrm{M}$

Sodium Silicate $\left(\mathrm{Na}_{2} \mathrm{SiO}_{3} 40 \%\right)$
Methods:
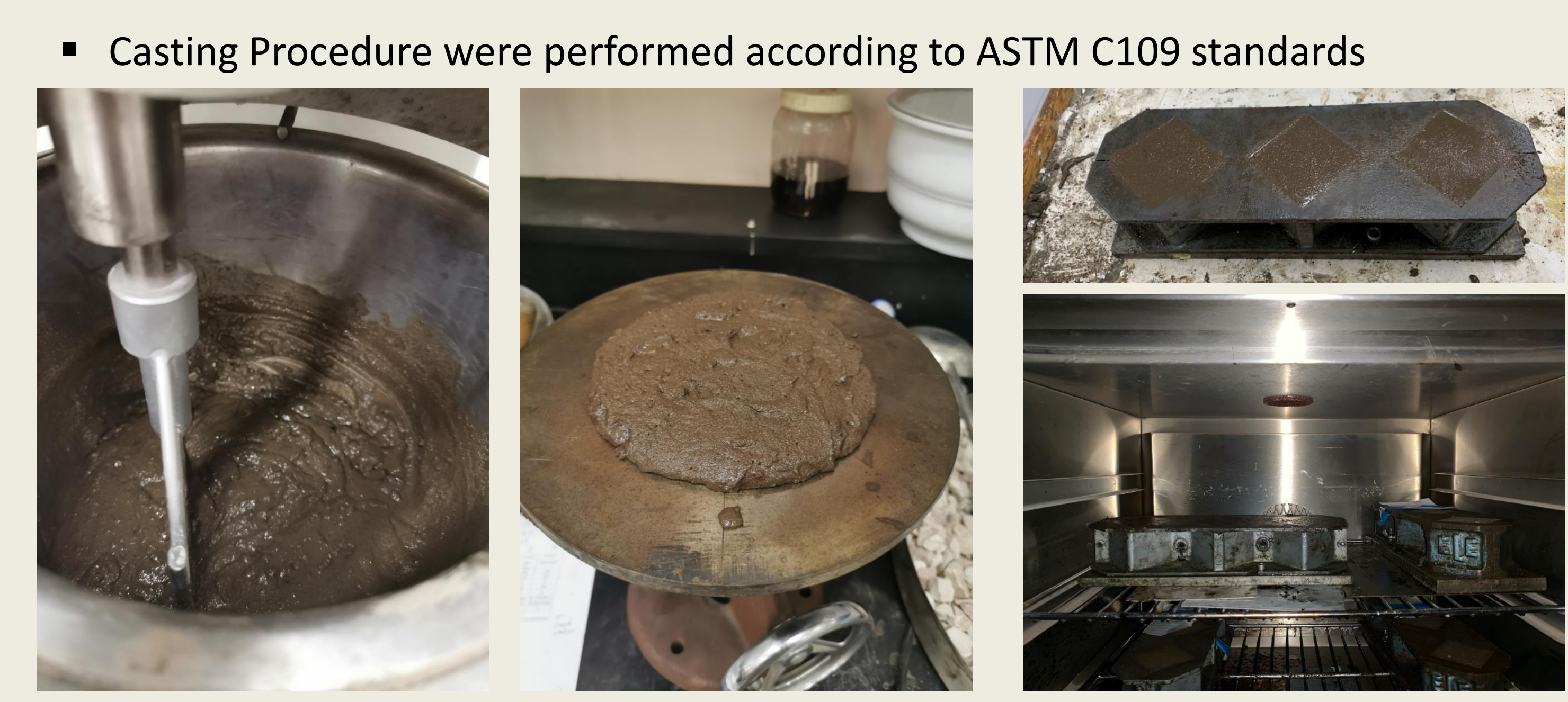

Curing conditions:

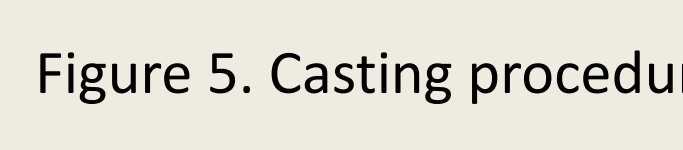

- Temperatures of 40,60 and $80^{\circ} \mathrm{C}(\mathrm{T})$

- Duration of 24,48 and $72 \mathrm{hrs}$. (D)

Mix designs:

Molarities of $\mathrm{NaOH}$ are 12, 14 and $16 \mathrm{M}$ (M)

- Sodium silicate/Sodium hydroxide ratios of 1,1.5, 2 and 2.5 (N)

\section{Results}

Effect of fluid to binder ratio, Sodium Hydroxide molarity, and Sodium Silicates to Sodium Hydroxide ratios on the compressive strength of geopolymer mortar are shown in Figures 6, 7 and 8 .

Effect of molarity (M) of $\mathrm{NaOH}$ solution and $\mathrm{Na}_{2} \mathrm{SiO}_{3} / \mathrm{NaOH}$ ratios (N)

Fluid to binder ratio $(F)=0.60$ :

- GPM activated with $16 \mathrm{M}$ exhibited the highest compressive strength of more than $60 \mathrm{MPa}$ for all sodium silicate to sodium hydroxide ratios of 1,1.5,2 and 2.5.

- Minimum Compressive strength of $33.4 \mathrm{MPa}$ for GPM activated with $12 \mathrm{M} \mathrm{NaOH}$ and with $\mathrm{Na}_{2} \mathrm{SiO}_{3} / \mathrm{NaOH}$ ratio of 1

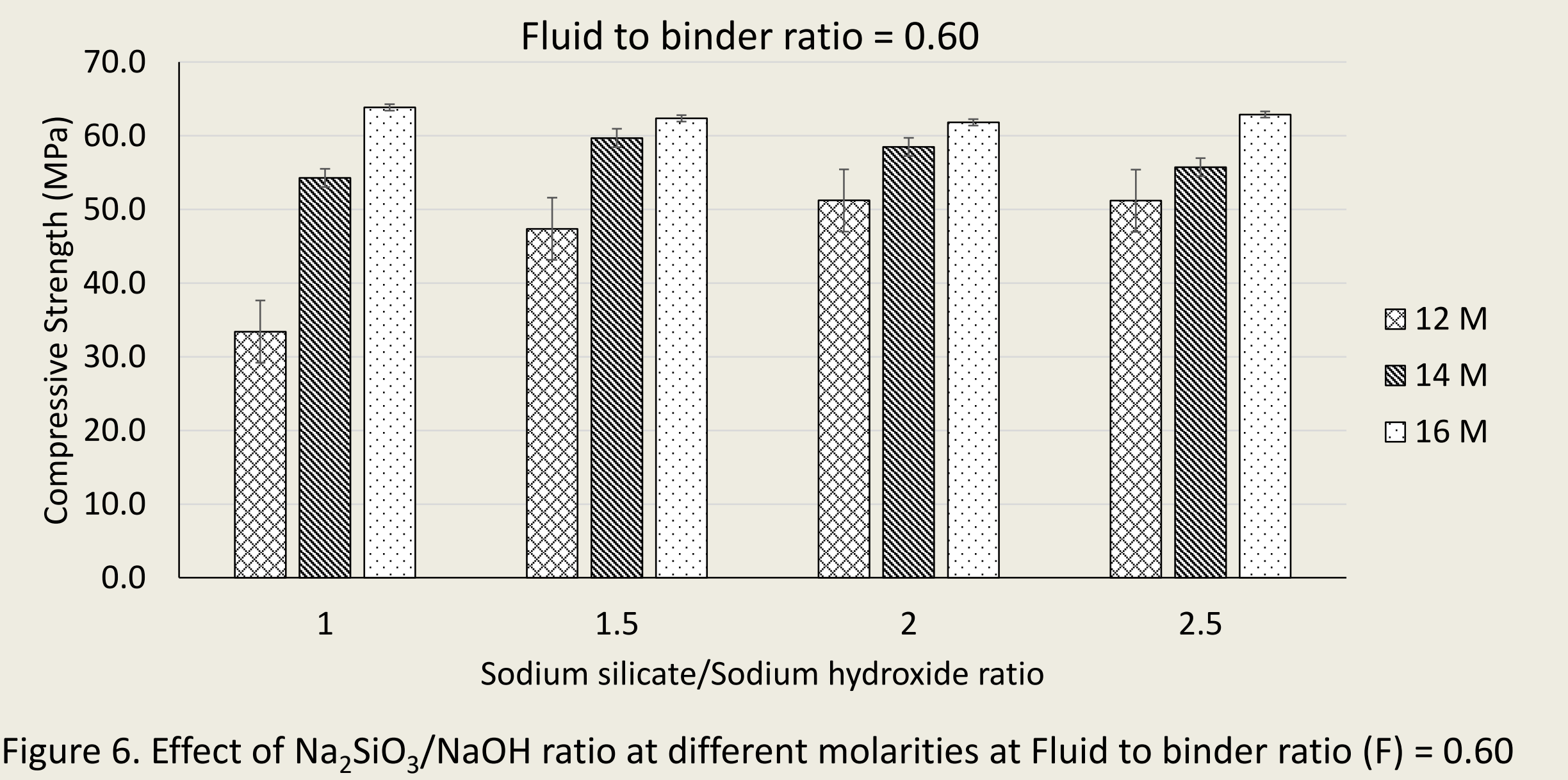

Effect of molarity (M) of $\mathrm{NaOH}$ solution and $\mathrm{Na}_{2} \mathrm{SiO}_{3} / \mathrm{NaOH}$ ratios (N):

Fluid to binder ratio $(F)=0.65$ :

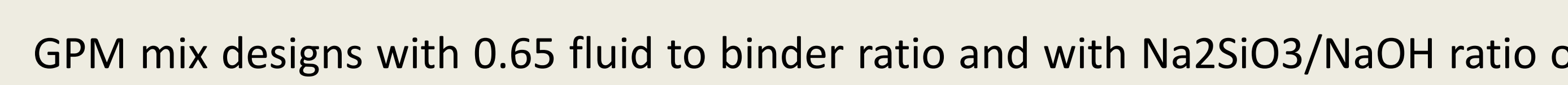
1 and 1.5 had little variations in the compressive strength.

Minimum Compressive strength of $45.1 \mathrm{MPa}$ for GPM activated with $14 \mathrm{M} \mathrm{NaOH}$ and with $\mathrm{Na2} \mathrm{SiO} 3 / \mathrm{NaOH}$ ratio of 1.

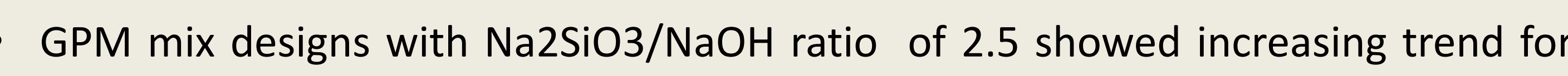
the compressive strength as the molarity increased.

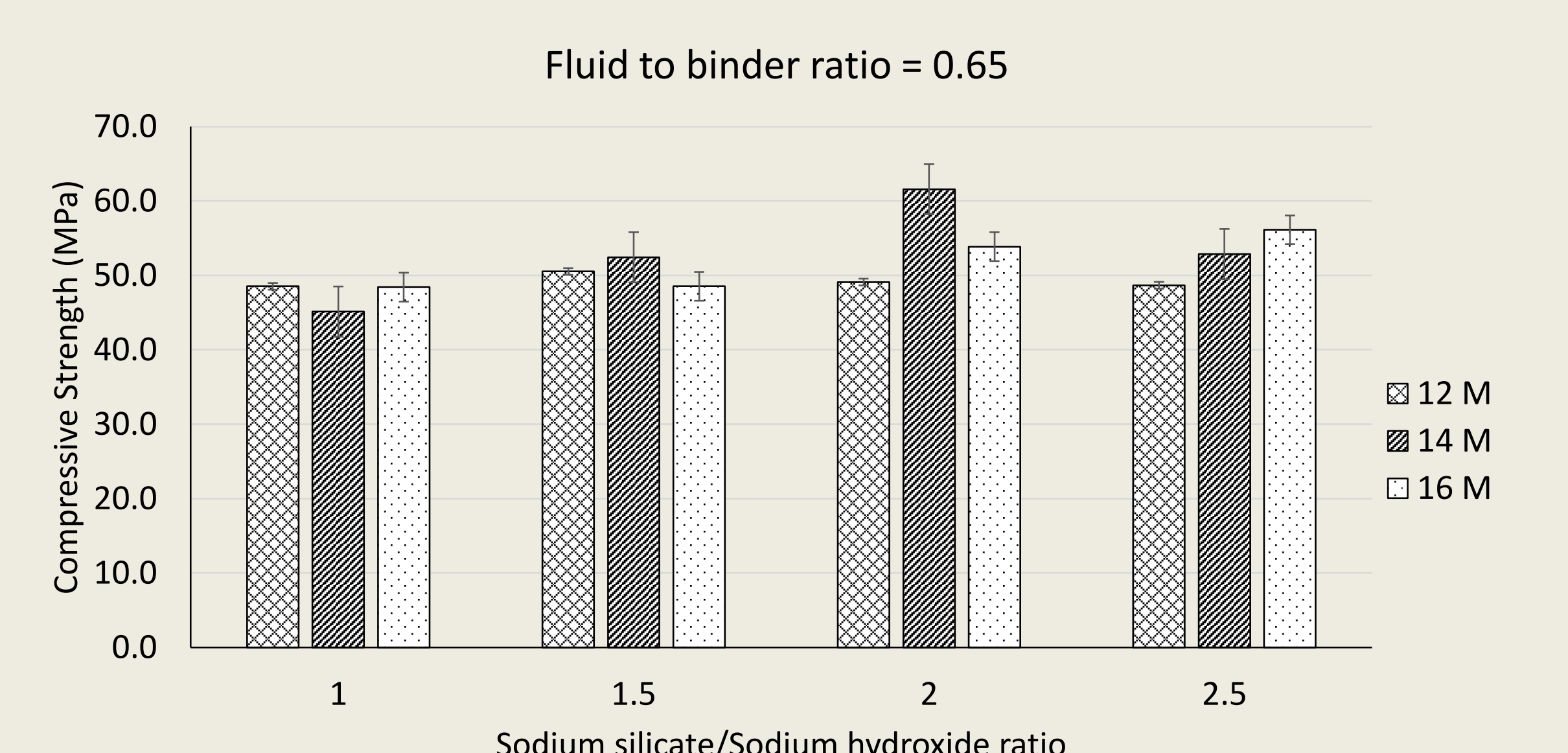

Figure 7. Effect of $\mathrm{Na}_{2} \mathrm{SiO}_{3} / \mathrm{NaOH}$ ratio at different molarities at Fluid to binder ratio $(\mathrm{F})=0.65$

Effect of molarity (M) of $\mathrm{NaOH}$ solution and $\mathrm{Na}_{2} \mathrm{SiO}_{3} / \mathrm{NaOH}$ ratios (N): Fluid to binder ratio $(F)=0.7$

- Fluid to binder ratio of 0.70 attained the lowest compressive strength.

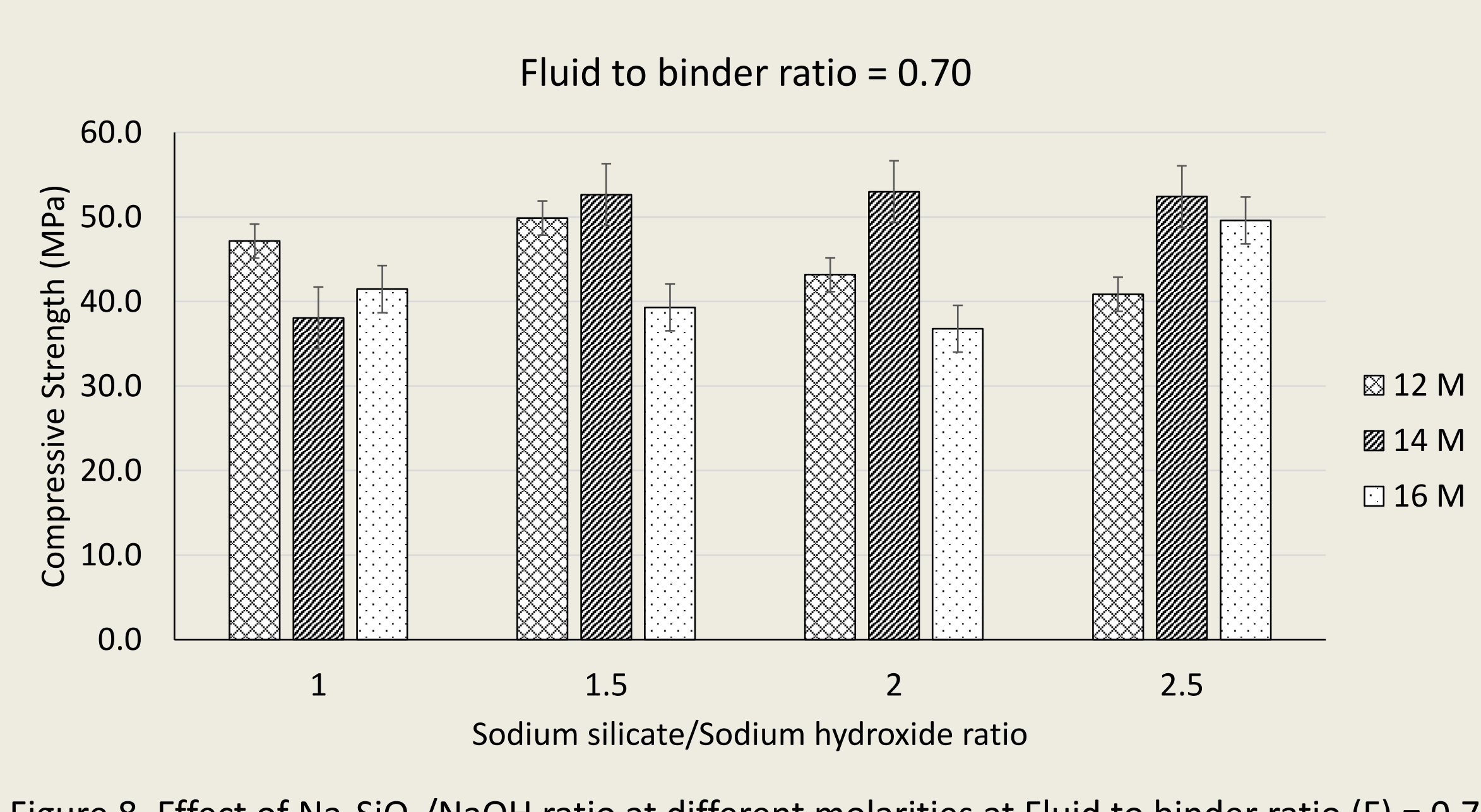

Effect of Curing conditions ( $T$ and $D)$ :

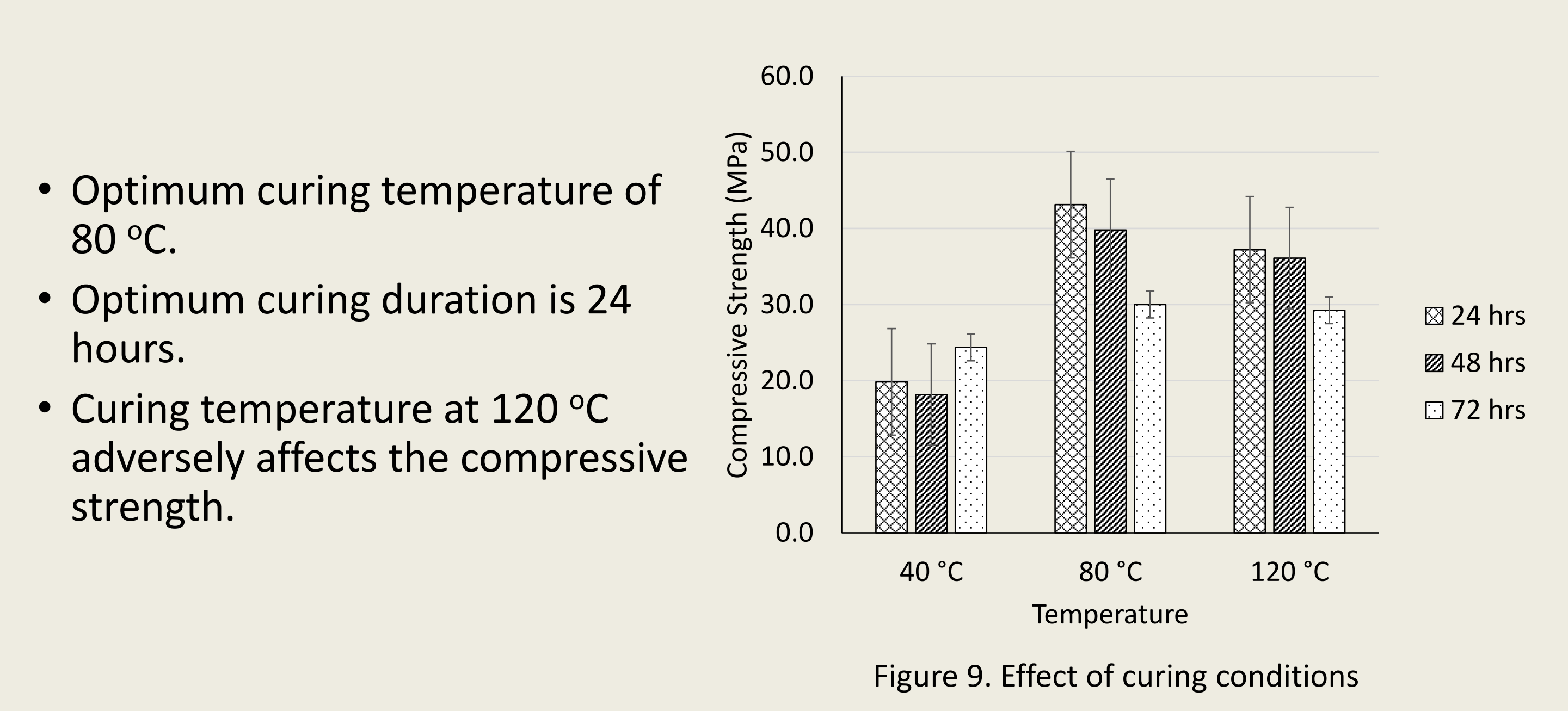

Effect of Age:

Early strength developmen

depends on the curing

At 28 days the strength

- Increase of $30 \%$ in the

compressive strength for Heat

curing.

Increase of $400 \%$ for Ambient

cured GPM Specimens

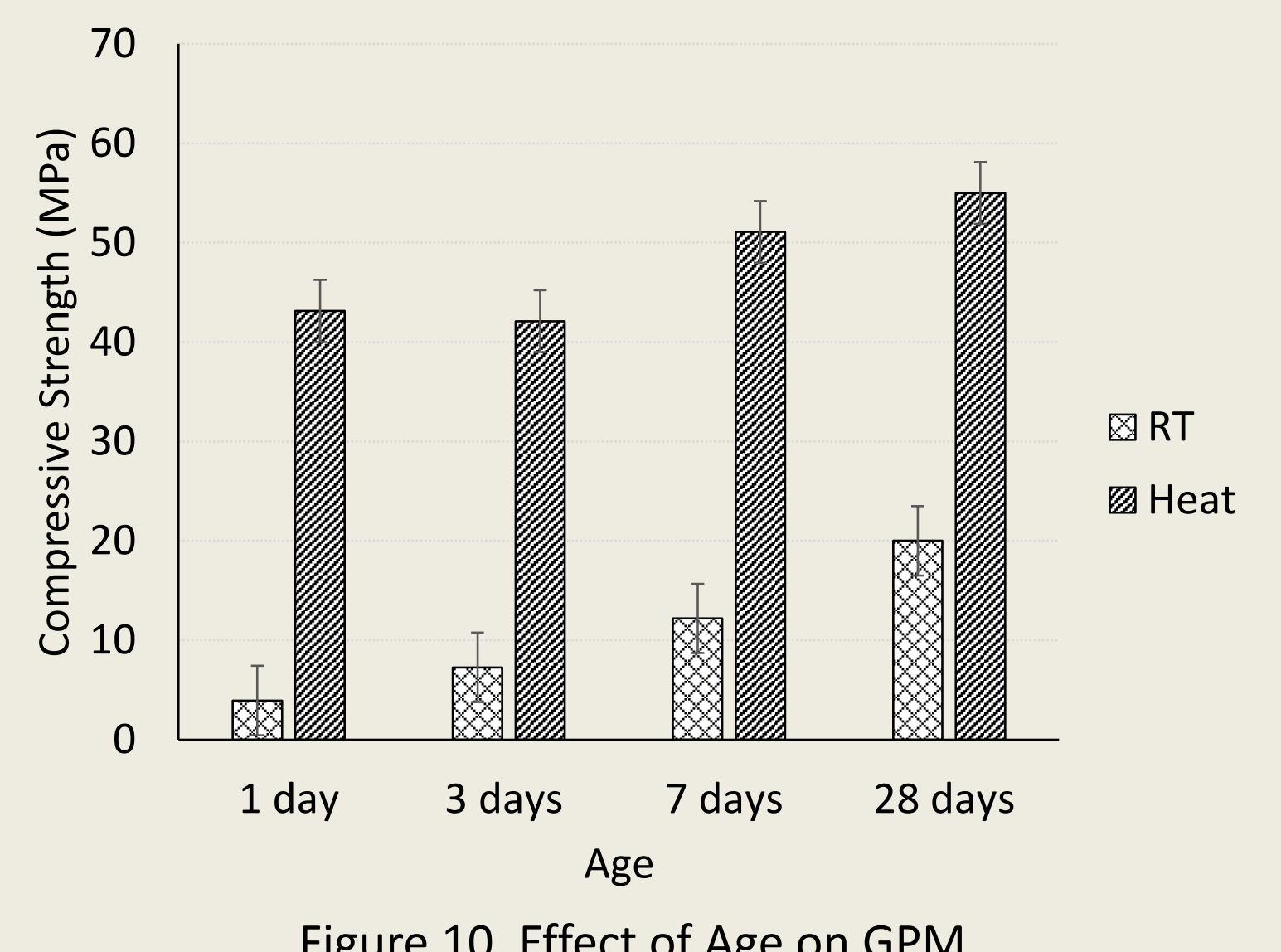

Scanning Electron Microscopy (SEM)

The effect of the
the SEM images.

The higher the molarity the better the microstructure of the GPM as the amount of reacted FA particles increased, and the less pores in the matrix observed as shown Figure 11
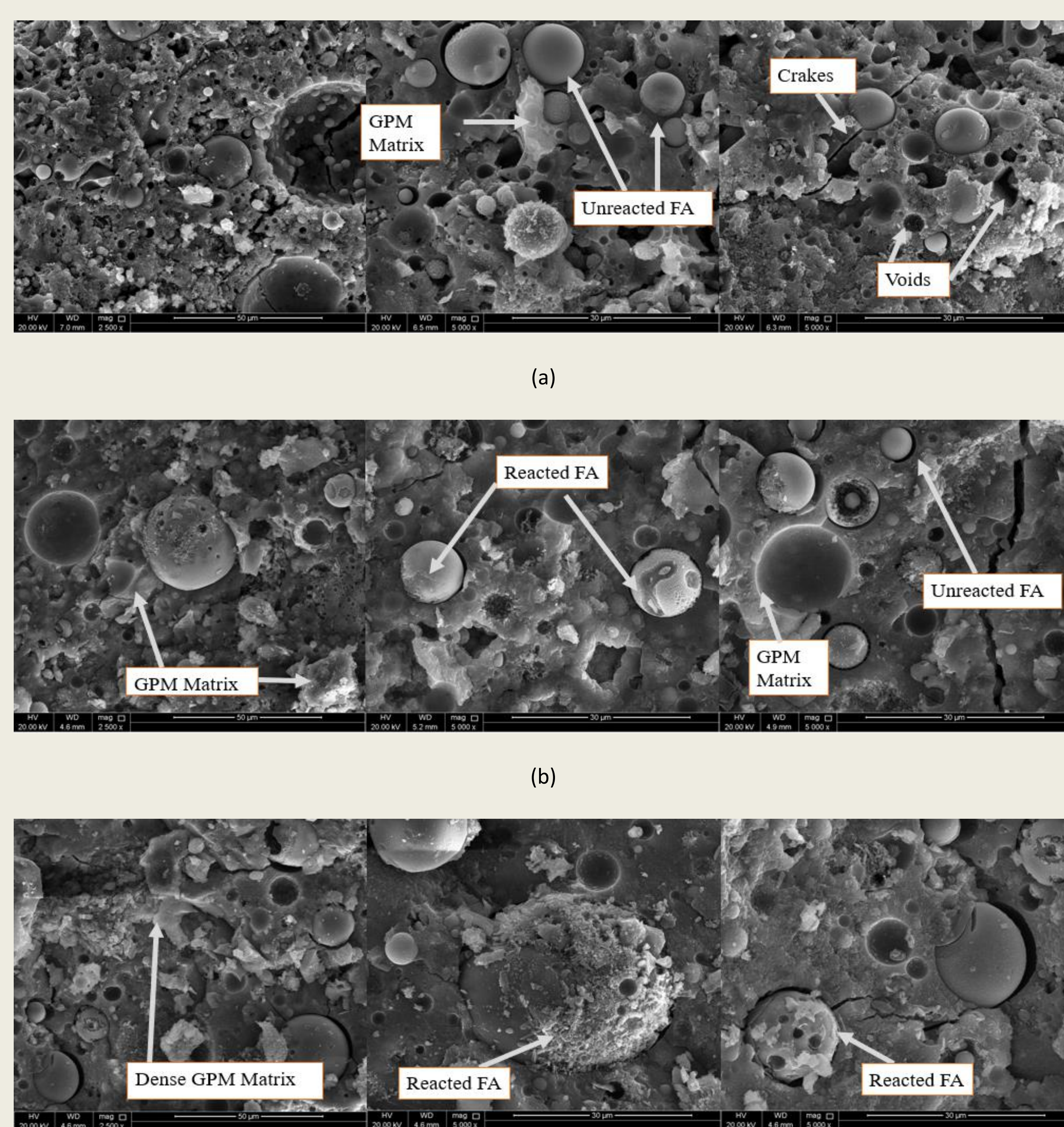

Figure 11. SEM Images of GPM specimens casted with (a) M1F1N1 (b) M2F1N1 (c) M3F1N

\section{Conclusion}

This study proves the efficacy of using Geopolymer mortar to replace the cement mortar in civil engineering applications, and the main findings are summarized below:

- The Molarity of the sodium hydroxide solution affects the compressive strength of GPM.

- The effect of fluid to binder ratio is a major contributor to the mechanica properties of GPM.

- Maximum early compressive strength of $63.9 \mathrm{MPa}$ was achieved by M3F1N 1 fluid to binder ratio of 0.60 and $\mathrm{Na}_{2} \mathrm{SiO}_{3} / \mathrm{NaOH}$ of 1 and $16 \mathrm{M} \mathrm{NaOH}$ solution.

- Heat curing is preferable to achieve early compressive strength for GPM.

- GPM gains strength with age for both heat curing and room temperature curing.

Fly ash made of Sodium hydroxide only has very low compressive strength compared to this made of both sodium hydroxide and sodium silicate, which is confirmed by SEM results.

GPM produced by fly ash shows very promising results that will ultimately be used in construction

\section{Acknowledgement}

This project was made possible by the support of Qatar University graduate studies office and the Center of Advanced Materials. We would like to thank SMEET Qatar for providing fly ash and Qatar Detergent Company for providing Sodium silicate solution. 